\title{
EXPERIMENTAL STUDY ON DIRECT SHEAR STRENGTH OF SEA ICE
}

\author{
by
}

\author{
HIROSHI SAEKI, TOSHIYUKI ONO
}

Department of Civil Engineering, Hokkaido University, Kita-13, Nishi-8, Kita-ku, Sapporo, Japan 060

NIU EN ZONG

Ministry of Communication, The People's Republic of China

\section{NAOKI NAKAZAWA}

Pacific Consultants Co Ltd, Mainichikaikan, Kita-4, Nishi-6, Kita-ku, Sapporo, Japan 060

\begin{abstract}
When structures such as oil drilling rigs are constructed on or through the ice plate in coastal and offshore regions, the shear strength of sea ice must be estimated to determine the loading on these structures. Testing methods for shear strength must be established so that shear strength of sea ice in various conditions can be determined.

The authors have been conducting, for five years, direct shear strength experiments using sea ice samples from the Okhotsk Sea coast. Physical characteristics of sea ice, including shear strength, depend to a great extent on such properties as salinity, porosity, grain size, etc; thus, there is variation in the test results of five years experimentation since the samples obtained varied from year to year.

The following conclusions were drawn from this experiment:
\end{abstract}

i) Under certain conditions the relation between shear strength and vertical stress can be represented by Coulomb's equation of soil; ie,

$$
\tau_{\mathrm{S}}=\mathrm{C}^{*}+\sigma_{\mathrm{v}} \cdot \tan \phi^{*}
$$

where $\tau_{\mathrm{S}}$ : shear strength, $\mathrm{C}^{*}:$ apparent cohesion (shear strength at $\left.\sigma_{v}=0\right), \Phi^{*}$ : angle of internal friction, $\sigma_{v}$ : vertical stress

ii) The shear strength of sea ice increases, approaching a constant, with decreasing ice temperature.

iii) The shear strength decreases with increasing ice shear area; an analogous relation exists in concrete.

iv) The shear strength is not greatly dependent on either the shear velocity or stress rate.

v) The shear strength is greater and generally increases more rapidly with decreasing ice temperatures in planes perpendicular to the ice growth direction than in planes parallel to it.

vi) Two types of failure occurred in the sea ice samples. In the case of (sample diameter)/(sample length) less than $2(\mathrm{~d} / \ell<2)$, the failure was induced by shear only. With $d / l>2$, the failure was not solely caused by shear since the existence of a small gap between the ice sample and shear box introduced a bending moment.

\section{INTRODUCTION}

In recent years, the development of seabed resources and the industrialization of cold regions have led to hydraulic structures, such as oil drilling platforms and artificial islands, being constructed in coastal and offshore areas exposed to sea ice pressure. These structures are being constructed directly on the ice sheet as well as founded on the seabed. Important in their design is estimation of the shear strength of sea ice. Shear strength is used in the calculation of the load-bearing capacity of the ice sheet as well as in estimating the horizontal pressure on structures built through the ice sheet. Testing methods to accurately estimate the shear strength of sea ice must be established, so that shear strength in various conditions can be determined.

Experiments were conducted in order to clarify the effects of the following:

i) the ratio of the diameter (d) to length (l) of the sea ice sample $(d / l)$
ii) diameter of the sea ice sample (d)
iii) shear velocity (க்s)
iv) shear stress rate $\left(\dot{\tau}_{s}\right)$
v) sea ice temperature $\left(\mathrm{T}^{\circ} \mathrm{C}\right)$
vi) vertical stress $\left(\sigma_{\mathbf{v}}\right)$
vii) growth direction of sea ice

\section{TESTING METHOD AND APPARATUS}

\section{Experimental Apparatus}

The experimental setup diagram is shown in Figure 1. The apparatus was designed to allow for the following:

i) use of variously sized sea ice samples

ii) variable vertical stress

iii) variable shear velocity

iv) variable shear stress rate

\section{Testing Procedure}

A horizontally movable shear box was used. Shear force was supplied by a hydraulic jack. The sea ice sample was placed in the circular hole in the shear box. Shear failure tests were conducted in this box. Static vertical loading was accomplished by placing weights on the sea ice sample via the steel cap. The shear velocity (thus, shear stress rate) was controlled by varying the hydraulic pressure applied to the jack.

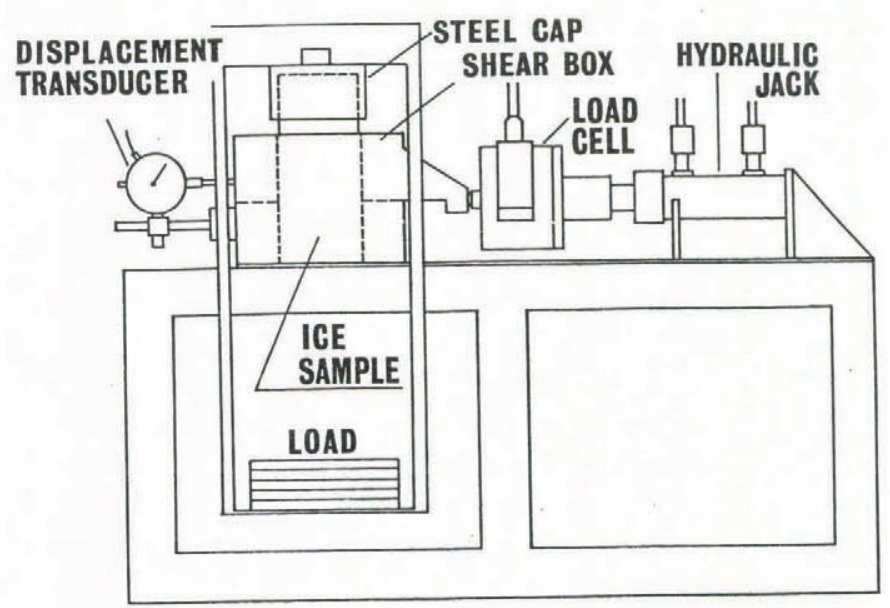

Fig.1. Diagram of the experimental setup. 


\section{Instrumentation}

The sea ice sample was held immobile by the fixed lower half of the shear box. Shear velocity was measured using a standard displacement transducer attached to the movable upper half of the shear box. The shearing force was measured using a standard load cell connected to the movable upper half of the shear box. The vertical load was measured by weighing the added weights, steel cap and associated structure.

\section{SEA ICE TEST SAMPLE}

Cylindrical ice samples were used because they are easy to obtain using a core drill and are less likely to become damaged. Ideally, rectangular ice samples are desirable to obtain strain rates uniform over the entire shear plane; thus, directly relating the effects of strain rate to the direct shear strength of sea ice. However, in practice it is very difficult to obtain rectangular prismatic samples that properly fit the rectangular hole of the shear box.

The original ice block was sawed from the Okhotsk Sea ice field (coastal). Sample diameters were $10.0 \mathrm{~cm}$ and $15.0 \mathrm{~cm}$, thicknesses were $3.0 \mathrm{~cm}, 5.0 \mathrm{~cm}$, $10.0 \mathrm{~cm}$ and $15.0 \mathrm{~cm}$. After a consideration of the grain size ( $8-12 \mathrm{~mm}$ in diameter) and ice sheet thickness $(40-50 \mathrm{~cm})$ of this sea ice, the standard sample's dimensions were chosen: diameter $10.0 \mathrm{~cm}$, thickness 15.0 $\mathrm{cm}$.

Figure 2 shows the coring directions of the sea ice sample: vertical and horizontal in relation to the upper

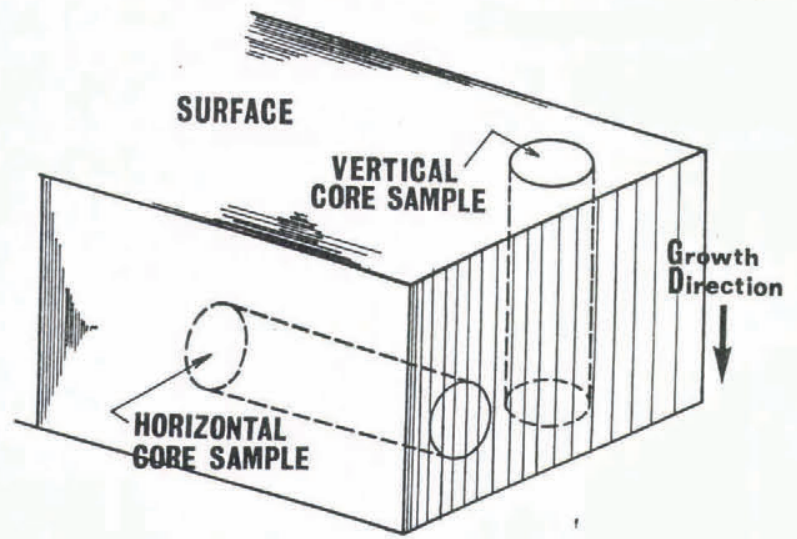

Fig.2. Diagram of the coring directions of the sea ice sample.

surface. The vertical core samples were tested

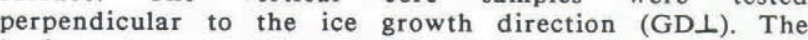
horizontal core samples were tested parallel to the ice growth direction $(\mathrm{GD} / /)$.

\section{TEST RESULTS}

\section{Diameter to length ratio effects}

Figure 3 shows the relation between the shear strength $\left(\tau_{S}\right)$ and the diameter (d) to length (l) ratio $(d / \ell)$ of the sea ice sample. Although the test results exhibit scatter, it can be seen that the smaller the ratio

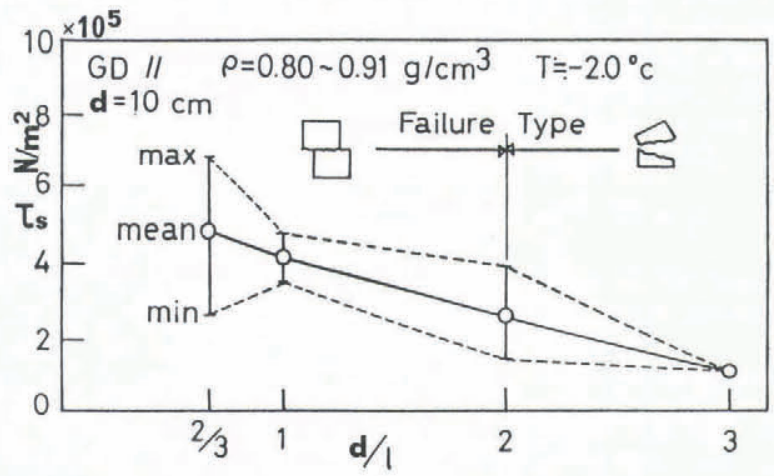

Fig.3. The relation between $\tau_{S}$ and $d / \ell$.

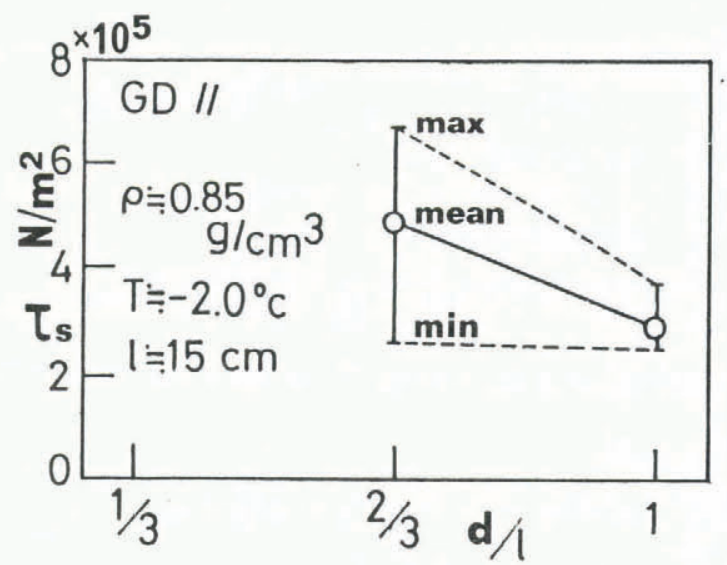

Fig.4. The relation between $\tau_{\mathrm{S}}$ and $\mathrm{d}$.

(d/l) becomes, the larger the value of $\tau_{s}$ becomes. Post experiment examinations of the fractured specimens showed two types of failure. In the case of $d / l<2$, the failure was induced by shear only; with $d / \ell>2$, the failure was not caused by shear alone since the existence of a small gap between the ice sample and shear box introduced a bending moment.

\section{Shear area effects}

Figure 4 shows the effects of the shear area on shear strength; ie the larger the ice sample diameter the smaller the value of $\tau_{s}$ became. An analogous relation exists in concrete. Future tests with larger sample diameters will have to be conducted to establish the relation between the $\tau_{S}$ of a test sample and the $\tau_{S}$ of the actual ice sheet.

\section{Shear velocity and stress rate effects}

Since ice is a visco-elastic solid, its shear strength varies with the strain rate $\dot{\boldsymbol{\epsilon}}$ and stress rate $\dot{\boldsymbol{\tau}}_{\mathrm{s}}$; thus, selection of the strain rate or stress rate is important when testing ice. When using cylindrical samples in direct shear tests, the strain rate over the plane of shear failure is not uniform; therefore, the authors determined the relation between $\tau_{s}$ and shear velocity $\dot{\delta}$ s.

The three values, the strain rate $\dot{\boldsymbol{\epsilon}}$, stress rate $\dot{\tau}_{\mathrm{s}}$ and shear velocity $\dot{\delta}$, are defined by the following equations:

$$
\begin{aligned}
& \text { strain rate : } \dot{\boldsymbol{\epsilon}} \\
& \dot{\boldsymbol{\epsilon}}=\frac{\Delta \ell}{\ell} \cdot \frac{1}{\mathrm{t}}
\end{aligned}
$$

where $\Delta \ell=$ strain, $\ell=$ shear length, $t=$ time to shear failure

$$
\begin{aligned}
& \text { stress rate : } \dot{\tau}_{S} \\
& \dot{\tau}_{S}=\tau_{S} / t
\end{aligned}
$$

where $\tau_{S}=$ direct shear strength, $t=$ time to shear failure

$$
\begin{aligned}
& \text { shear velocity : } \dot{\delta s} \\
& \dot{\delta} s=\Delta \ell / \mathrm{t}
\end{aligned}
$$

where $\Delta l=$ strain, $t=$ time to shear failure

Figure 5 shows the effects of shear velocity $\delta$ on the shear strength. It can be seen that the shear strength $T_{S}$ is relatively insensitive to changes in shear velocity in the range 0.01 to $1.0 \mathrm{~mm} / \mathrm{s} ; \tau_{\mathrm{s}}$ broadly peaks about $0.1 \mathrm{~mm} / \mathrm{s}$.

Converting the sample's circular cross section to an equivalent square cross section produces an equivalent shear length B, where B is derived as follows:

$$
B=\sqrt{\pi} \cdot d \cdot 2
$$

where $d=$ diameter of the ice sample. 


$$
\begin{aligned}
& \left.\sum_{10}^{N}\right|^{\times 10^{5}} \text { o } 0 \text { ० } 8 \text { ०0-8-8.0.8-8. }
\end{aligned}
$$

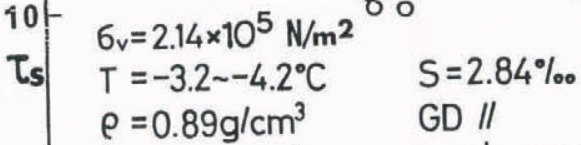

$$
\begin{aligned}
& { }_{0} \frac{1}{0.01} \quad 0.1 \quad \delta \dot{s} \quad 1.0 \times 10^{-3} \mathrm{~m} / \mathrm{s}
\end{aligned}
$$

Fig.5. Effects of shear velocity $\dot{\delta}_{S}$ on the shear strength $\tau_{\mathrm{S}}$.

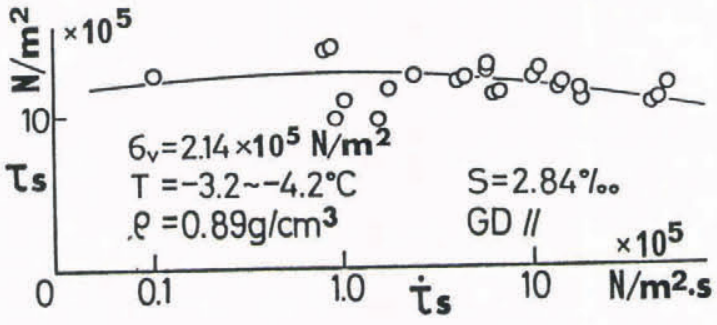

Fig.6. Effects of shear stress rate $\dot{\tau}_{S}$ on the shear strength Ts.

Using this shear length $B$ in Equation 1 produces a strain rate of $\dot{\epsilon}$ of $0.001 \mathrm{sec}^{-1}$ at the maximum shear strength $\tau_{\mathrm{s}}$. This value coincides with the rates found in compressive strength tests.

The relation between $\tau_{\mathrm{s}}$ and shear stress rate $\dot{T}_{\mathrm{s}}$ is shown in Figure 6 . The shear strength $T_{S}$ is relatively insensitive to changes in shear stress rate $\dot{\tau}_{s}$ in the range $0.1 \times 10^{5}$ to $10 \times 10^{5} \mathrm{~N} / \mathrm{m}^{2}$.s.

Sea ice temperature effects

In general, the strength of ice depends on its temperature. The experimental relation between the shear strength and ice temperature is shown in Figure 7 . Descriptively, the figure can be divided into two temperature regions: $-2^{\circ} \mathrm{C}>\mathrm{T}>-6^{\circ} \mathrm{C}$ and $\mathrm{T}<-6^{\circ} \mathrm{C}$ The shear strength clearly increases between $-2^{\circ} \mathrm{C}$ and $-6^{\circ} \mathrm{C}$, but generally remains constant or decreases for $\mathrm{T}$ $<-6{ }^{\circ} \mathrm{C}$. This phenomenon for $\mathrm{T}<-6^{\circ} \mathrm{C}$, the remaining constant or decreasing of $\tau_{\mathrm{S}}$, appears to be caused by the dilitancy of sea ice.

\section{Vertical stress effects}

The experimental relations between the shear strength $\tau_{S}$ and vertical stress $\sigma_{y}$, as a function of ice temperature $\mathrm{T}$, are shown in Figure $8(\mathrm{a})$ for 1981 and in Figure 8(b) for 1982. As can be seen, $\tau_{S}$ increases with decreasing ice temperature T. $\tau_{S}$ increases linearly with increasing vertical stress $\sigma_{v}$ for ice temperatures

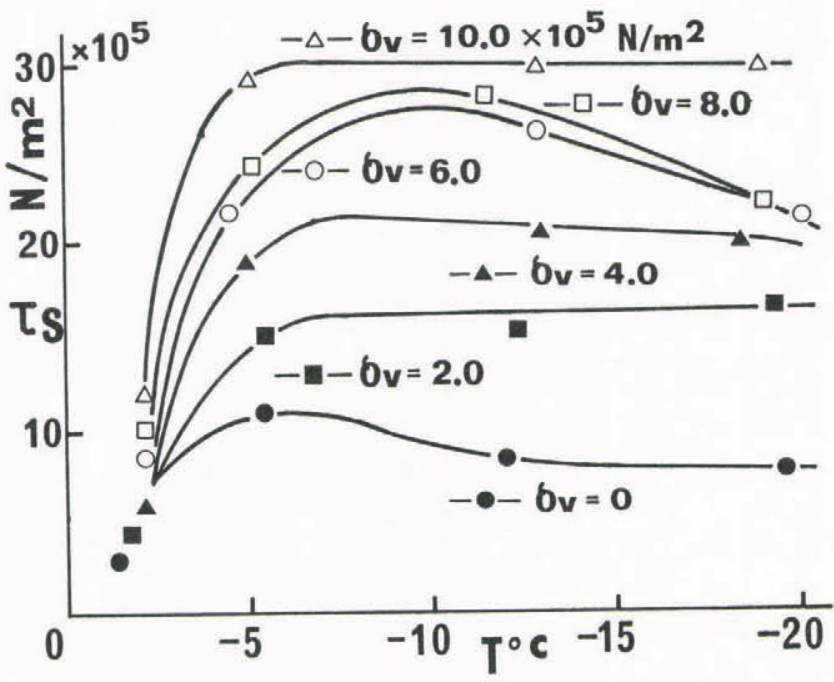

Fig.7. Relation of $T_{S}$ and $T$ as a function of $\sigma_{v}$.

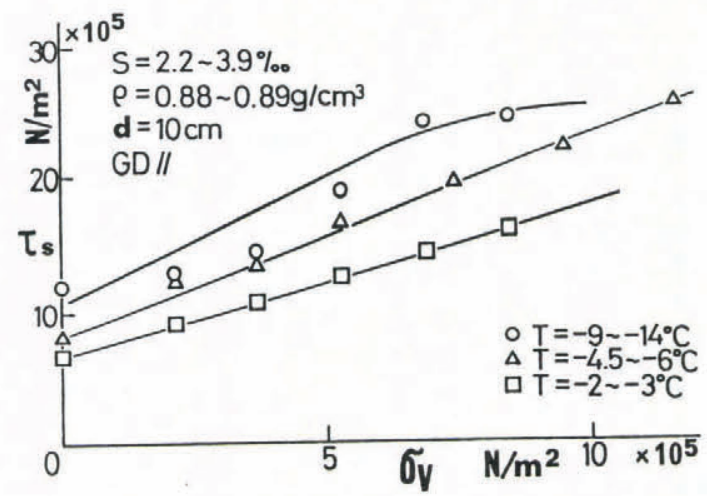

Fig.8(a). Relation of $T_{S}$ and $\sigma_{\mathrm{v}}$ as a function of $\mathrm{T}$ (1981).

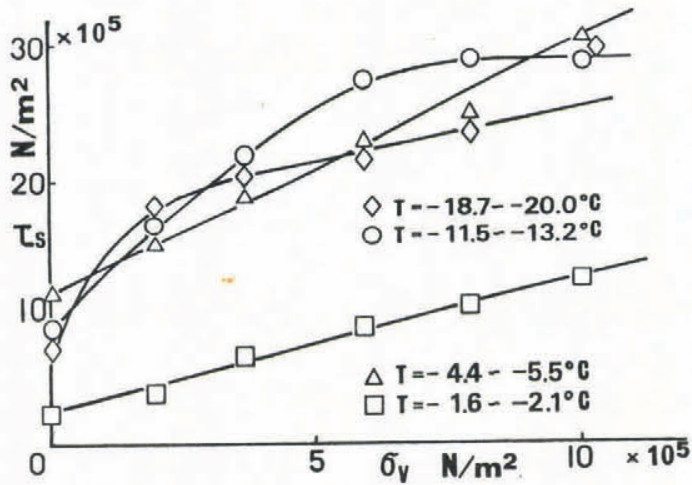

Fig.8(b). Relation of $T_{S}$ and $\sigma_{v}$ as a function of $T$ (1982).

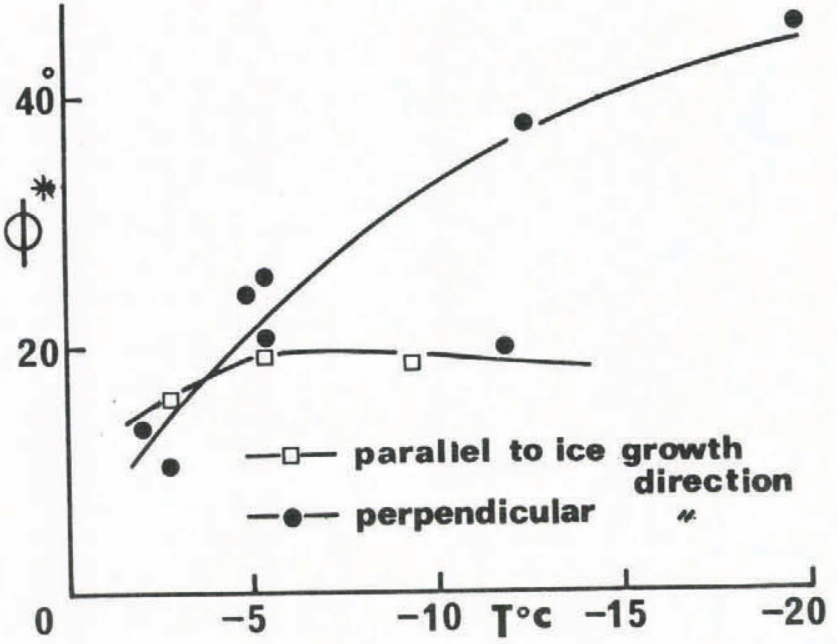

Fig.9. Relation between $\phi^{*}$ and $\mathrm{T}$.

higher than about $-6^{\circ} \mathrm{C}$; at lower ice temperatures $\left(-9^{\circ} \mathrm{C}\right.$ to $-14^{\circ} \mathrm{C}$ in Figure $8(\mathrm{a})$ and $-11^{\circ} \mathrm{C}$ to $-20^{\circ} \mathrm{C}$ in Figure 8 (b) the relation between $\tau_{S}$ and $\sigma_{y}$ is not linear. The results (at temperatures higher than about $-6^{\circ} \mathrm{C}$ ) coincide with Coulomb's equation for direct shear strength; i.e., $\tau_{\mathrm{S}}$ and $\sigma_{\mathrm{y}}$ are linearly dependent.

Coulomb's equation:

$\tau_{\mathrm{S}}=\mathrm{C}^{*}+\sigma_{\mathrm{v}} \cdot \tan \phi^{*}$

where $C^{*}=$ apparent cohesion, $\phi^{*}=$ angle of internal friction, $\sigma_{\mathrm{v}}=$ vertical stress.

Relation between $\Phi^{*}$ and $\mathrm{T}$

The relation between the angle of internal friction $\Phi^{*}$ and ice temperature $T$ is shown in Figure 9. It can be seen that $\Phi^{*}$ increases with decreasing ice temperature when the shear force is applied perpendicular to the 


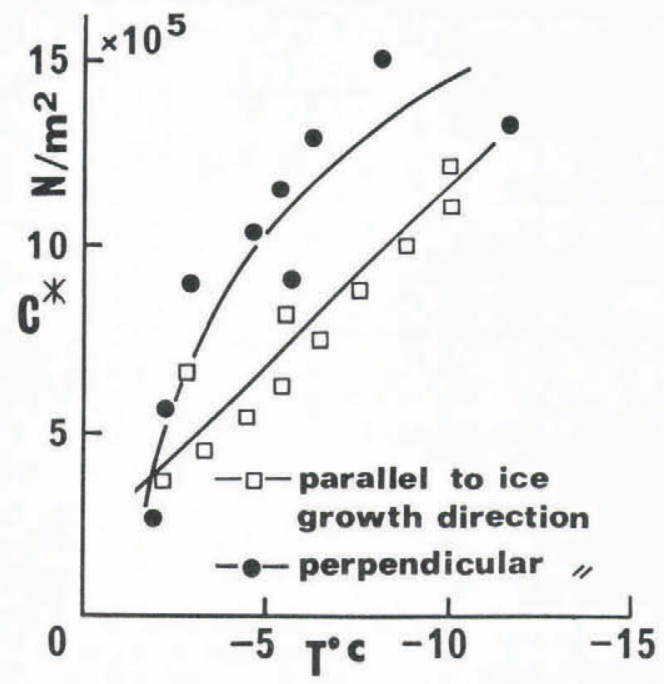

Fig.10. Relation between $\mathrm{C}^{*}$ and $\mathrm{T}$.

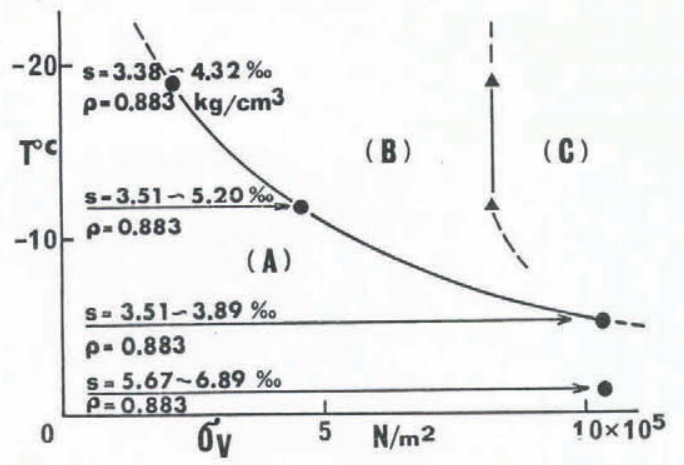

Fig.11. Application envelope of Coulomb's equation.

growth direction. With the shear force applied parallel to the growth direction, $\Phi^{*}$ tends to remain almost constant.

Growth direction effects on $\mathrm{C}^{*}$

Figure 10 shows the results of the growth direction effect test on $C^{*}$; ie, $\tau_{S}$ at $\sigma_{y}=0$. Although the test results exhibit scatter, it can be seen that $C^{*}$ in shear planes perpendicular to the growth direction is generally greater than $C^{*}$ in planes parallel to the growth direction (at equivalent sample temperatures). With

TABLE 1. RESULTS OF FIVE YEARS OF SEA ICE EXPERIMENTS

\begin{tabular}{|c|c|c|c|c|c|c|}
\hline YEAR & 0 & $5(\%)$ & $c^{*} \times 10^{5}$ & $\phi^{* 1}$ & $T\left({ }^{\circ} \mathrm{C}\right)$ & $\sigma_{v} \times 10^{5}$ \\
\hline 1978 & 0.850 & $2.50-6.00$ & $\begin{array}{l}3.40 \\
4.30 \\
5.30 \\
6.20 \\
7.10 \\
8.00 \\
9.00 \\
9.90\end{array}$ & $\mid \begin{array}{l}- \\
- \\
- \\
- \\
- \\
- \\
- \\
-\end{array}$ & $\begin{array}{l}-2.0 \\
-3.0 \\
-4.0 \\
-5.0 \\
-6.0 \\
-7.0 \\
-8.0 \\
-9.0\end{array}$ & $\begin{array}{l}0 \\
0 \\
0 \\
0 \\
0 \\
0 \\
0 \\
0\end{array}$ \\
\hline 1979 & 0.860 & $3.60 \sim 6.30$ & $\begin{array}{r}5.30 \\
10.50 \\
12.30 \\
15.40 \\
\end{array}$ & $\begin{array}{l}-1 \\
- \\
- \\
-1\end{array}$ & $\begin{array}{l}-2.0 \\
-4.0 \\
-6.0 \\
-8.0\end{array}$ & $\begin{array}{l}0 \\
0 \\
0 \\
0\end{array}$ \\
\hline 1980 & 0.880 & 2.00 & $\begin{array}{l}9.68 \\
8.74 \\
\end{array}$ & & $-6.0 \sim-8.0$ & $\begin{array}{l}0 \\
0\end{array}$ \\
\hline 1981 & 0.880 & $\begin{array}{c}2.20-3.90 \\
2.40 \sim 3.40 \\
2.25 \\
2.40 \sim 3.90 \\
0.89 \\
3.28\end{array}$ & $\begin{array}{r}6.60 \\
8.20 \\
11.40 \\
9.00 \\
9.20 \\
12.60 \\
\end{array}$ & $\mid \begin{array}{l}101 \\
211 \\
20 \\
10 \\
26 \\
21\end{array}$ & $\begin{array}{l}-2.0 \sim-3.0 \\
-4.5 \sim-6.0 \\
-8.0 \sim-10.5 \\
-2.0 \sim-3.0 \\
-4.5 \sim-6.0 \\
-9.0 \sim-14.0\end{array}$ & $\begin{array}{l}0-8.4 \\
0-11.6 \\
0-8.5 \\
0 \sim 8.5 \\
0-11.6 \\
0-8.5\end{array}$ \\
\hline 1982 & 0.883 & $\begin{array}{l}5.67-6.89 \\
3.51-3.89 \\
3.51-5.20 \\
3.38-4.32\end{array}$ & $\begin{array}{r}2.60 \\
11.20 \\
8.80 \\
7.70 \\
\end{array}$ & $\begin{array}{l}131 \\
25 \\
42 \\
53 \\
\end{array}$ & $\begin{array}{r}-1.6 \sim-2.1 \\
-4.4 \sim-5.5 \\
-11.5 \sim-13.2 \\
-18.7 \sim-20.0\end{array}$ & $\begin{array}{l}0-10.2 \\
0-10.2 \\
0-10.2 \\
0-10.2\end{array}$ \\
\hline
\end{tabular}

decreasing sample temperatures, the $C^{*}$ in planes perpendicular to the growth direction tends to increase more rapidly than in planes parallel to the growth direction.

\section{CONCLUSION}

The application envelope of Coulomb's equation

As determined from the results of five years of sea ice experiments summarized in Table 1 , the application envelope of Coulomb's equation is shown in Figure 11. In region A, Coulomb's equation is applicable for the determination of the shear strength of sea ice. The shear strength in region $C$ is independent of vertical stress $\sigma_{v}$. In region $B$, the relation between $\tau_{S}$ and $\sigma_{y}$ is not linear because of the dilitancy of sea ice.

Ice temperature

The shear strength of sea ice increases, approaching a constant, with decreasing ice temperature (see TEST RESULTS - 4).

\section{Shear velocity and stress rate}

The shear strength is not greatly dependent on either the shear velocity or stress rate (see TEST RESULTS - 3).

\section{Growth direction of sea ice}

The shear strength in planes perpendicular to the growth direction is generally greater than in planes parallel to the growth direction (see TEST RESULTS 7).

\section{Shear Area}

The shear area experimental results (see TEST RESULTS - 2) indicate that the shear strength decreases with increasing shear area. Analogous relation exists in concrete.

Diameter to length ratio

The smaller the ratio $(d / \ell)$ becomes, the larger the value of $T_{S}$ becomes (see TEST RESULTS - 1).

\section{ACKNOWLEDGEMENT}

The authors express their appreciation to E. Suenaga for his assistance in the preparation of this paper. 